\title{
Studies on the Sedative Effect of Mitragyna speciosa Korth. as an Endemic Plant in West Borneo, Indonesia
}

\author{
Dini Novindriani ${ }^{1}$, Dini Novindriana ${ }^{1}$, Bambang Wijianto ${ }^{2, *}$, Mohammad Andrie ${ }^{3}$ \\ 1 Student of pharmacy Universitas Tanjungpura, Indonesia \\ 2 Department of Pharmaceutical Chemistry, Universitas Tanjungpura, Indonesia; bam.wijianto@gmail.com (B.W.); \\ 3 Department of pharmacology, Universitas Tanjungpura; andreparaoh@gmail.com (M.A.); \\ * Correspondence: bam.wijianto@gmail.com (B.W.);
}

Scopus Author ID 57217736884

Received: 1.08.2021; Revised: 28.08.2021; Accepted: 30.08.2021; Published: 4.09.2021

\begin{abstract}
Kratom (Mitragyna speciosa Korth.) is an endemic plant of West Borneo (Indonesia). One of its uses in the community is as a sedative. The aim of this research is to determine the effective dose of kratom leaf extract and infusion against male BALB/c mice. The traction test and fireplace test methods were used to determine the sedative effect quantitatively. The qualitative test was carried out by observing the corneal reflex and the body turning reflex. Mice were divided into 5 groups, namely positive control group (diazepam), negative control (CMC 1\% + aqua dest), ethanol extract group 12.14 $\mathrm{mg} / 20 \mathrm{gBB}$, ethanol extract group $24.29 \mathrm{mg} / 20 \mathrm{gBB}$, ethanol extract group $48.57 \mathrm{mg} / 20 \mathrm{gBB}$, kratom leaf infusion group $39 \mathrm{mg} / 20 \mathrm{gBB}$, kratom leaf infusion group $78 \mathrm{mg} / 20 \mathrm{gBB}$, and kratom leaf infusion group $156 \mathrm{mg} / 20 \mathrm{gBB}$. The results showed that the ethanol extract and infusion of kratom leaf had a sedative effect on male BALB/c mice. The effective doses of ethanolic extract and kratom leaf infusion are $48.57 \mathrm{mg} / 20 \mathrm{gBB}$ and $156 \mathrm{mg} / 20 \mathrm{~g} \mathrm{BW}$, respectively. Kratom leaf ethanolic extract has more potential sedative effect than diazepam as a positive control, whereas kratom leaf infusion is the opposite.
\end{abstract}

Keywords: sedative effect; Mitragyna speciosa Korth.; traction test; fireplace test.

(C) 2021 by the authors. This article is an open-access article distributed under the terms and conditions of the Creative Commons Attribution (CC BY) license (https://creativecommons.org/licenses/by/4.0/).

\section{Introduction}

The Covid-19 pandemic has created a new problem globally, namely stress. Sleep disturbance or insomnia is a disease problem caused by stress. Insomnia is a condition in which a person cannot sleep comfortably accompanied by symptoms such as feeling tired and tired all day long and continuously. This condition is also characterized by difficulty sleeping again when waking up in the middle of the night [1-4].

Insomnia is closely related to mental and physical health. There is literature concluding that insomnia with short sleep duration is associated with activation of both limbs of the stress system and other physiological hyperarousal indices, which can adversely affect physical and mental health, namely the risk of cardiometabolic and neurocognitive morbidity and mortality $[1,4]$. However, insomnia is more commonly associated with psychiatric disorders than any other medical illness.

Pharmacotherapy with benzodiazepine receptor agonists is the most feasible and effective treatment option for insomnia [5-7]. Benzodiazepines bind to GABA receptors. Benzodiazepines decrease GABA inhibitory activity by binding to $\gamma$-aminobutyric acid 
receptors $\left(\mathrm{GABA}_{\mathrm{A}} \mathrm{Rs}\right)$ and GABA gated chloride/bicarbonate channels. This situation causes chloride ions to enter the cells to spur hyperpolarization and inhibit neuron explosion.

From a medical perspective, the thing that needs to be considered in the use of sedativehypnotic drugs is the emergence of side effects that are quite dangerous for the wearer, such as habituation, tolerance, and even addiction. Meanwhile, from the non-medical aspect that needs attention is the emergence of drug abuse which is now increasingly prevalent in society [8]. Reflecting on these conditions, it is necessary to have traditional medicine as an alternative treatment with minimum side effects, more effective, safe, cheap, and easy to obtain to reduce the problem. Moreover, the plants used are endemic to the region.

One of the medicinal plants that have been used to treat various diseases is the kratom plant (Mitragyna speciosa Korth.). Kratom is an endemic plant in Southeast Asia such as Thailand, Malaysia, and Indonesia [9-12]. Empirically, fresh or dried kratom leaves can be chewed, brewed into tea, or made into cigarettes. Kratom is used in folk medicine as a stimulant at low doses, and at high doses, it can have a sedative effect. The chemical contains Kratom leaves (Mitragyna speciosa Korth.) are alkaloids, saponins, flavonoids, triterpenoids, and glycoside derivatives $[12,13]$. Publications claim that the alkaloid mitragynine is responsible for its pharmacological effects, one of which is its sedative effect [10-12, 14-16]. This study aims to determine the effective dose of ethanol extract and kratom leaf infusion against BALB/c mice and their potential as an alternative to benzodiazepine drugs substituted.

\section{Materials and Methods}

\subsection{Plant samples.}

Leaves used are wild green leaves with red leaf bones in Sibau Hilir, Putusibau, Kapuas Hulu-West Borneo. Leaf samples were taken during the rainy season in the morning of June. The sample obtained was determined in the Biology Laboratory of the Faculty of Mathematics and Natural Sciences, Universitas Tanjungpura, Pontianak.

\subsection{Chemical, reagents, and animal testing.}

Carboxymethyl cellulose, 1\% ammonia solution, hydrochloric acid 2N, chloroform, Mayer reagent, Dragendrof reagent, magnesium powder, Lieberman-Burchard reagent, ether, $\mathrm{FeCl}_{3}$, and diazepam as control were purchased from Merck. The animal testing used in this study were male mice of the BALB / c strain.

\subsection{Preparation of extract and infusion of kratom leaves.}

Making an infusion is done by weighing $31.2 \mathrm{~g}$ of kratom leaf powder and putting it in the infusion pan and heated in a water bath for 15 minutes at a temperature of $90^{\circ} \mathrm{C}$. The extract was made by weighing $200 \mathrm{~g}$ of kratom leaf dry powder and then macerated with $70 \%$ ethanol at room temperature for 3 days. The solvent is replaced every $1 \times 24$ hours. The macerate is then concentrated in an evaporator at $60^{\circ} \mathrm{C}$.

The extraction process itself has carried out a total of 200 grams of dried Simplicia powder of kratom leaves was macerated with $70 \%$ ethanol extract at room temperature for three days with solvent replacement every 1 x 24 hours, namely the first day of $1300 \mathrm{ml}$ and the second and third days of $1000 \mathrm{ml}$ each. The macerate is then concentrated with an evaporator at a temperature of $60^{\circ} \mathrm{C}$. 


\subsection{Traction test.}

The front arm/leg of the test animal is hanging from a horizontally stretched wire. Abnormal test animals will take a long time to turn around and need a fast time to fall. That fact indicates that the test animals are under the influence of the sedative effect (positive) $[17,18]$.

\subsection{Fireplace test.}

The test animal is placed in a cylindrical glass. Observations were made by looking at the time required for the test animal to jump out of the glass tube. Normal test animals will immediately run away and climb the cylinder glass, while the test animals affected by the sedative effect will climb the glass for a longer time [19,20]

\section{Results and Discussion}

Based on the results of sample determination conducted at the Biology Laboratory, Faculty of Mathematics and Natural Sciences (FMIPA), Universitas Tanjungpura, it was stated that the plant used in this study was the Kratom leaves (Mitragyna speciosa Korth.).

Macroscopic test of kratom leaf by organoleptic gave an astringent taste, green-brown leaf color, an atypical odor like the smell of leaves in general, and visually in the form of coarse powder.

\subsection{Phytochemical screening results.}

Kratom leaf infusion contains chemical compounds of flavonoids, polyphenols, alkaloids, tannins, and saponins. While the ethanol extract, in addition to containing the compounds contained in the infusion, also contains steroids. The results of the phytochemical screening can be seen in table 1 .

Table 1. Phytochemical Screening Results.

\begin{tabular}{l|l|c|c}
\multirow{2}{*}{ Test } & \multirow{2}{*}{ Reagent } & \multicolumn{2}{c}{ Result } \\
\cline { 2 - 4 } & & Extract ethanolic & Infusion \\
\hline \multirow{2}{*}{ Alkaloid } & Dragendroff & + & + \\
\cline { 2 - 4 } & Mayer & + & + \\
\cline { 2 - 4 } & Wagner & + & + \\
\hline Flavonoid & Molish & + & + \\
\hline Polyphenol & FeCl 3 & + & - \\
\hline Steroid & Liberman-Burchard & + & + \\
\hline Saponin & Water & + & +
\end{tabular}

\subsection{Sedative effect test result.}

The sedative effect was tested using the Traction test and Fireplace test methods, and corneal reflex and back reflex tests were taken as qualitative data. The parameters for testing are the length of time it takes the test animal to turn around, and the time it takes the test animal to fall, while the test parameter using the fireplace test method is the length of time it takes the test animal to jump out of the tube. The longer it takes the test animal to turn around and jump out of the tube, and the faster it takes the test animal to fall, it means that the effect of the sedative effect is also getting more significant. 
In the ethanolic extract, the results of the Anova test for all parameters were differences in the length of turning time, falling time, and jumping time between the treatment groups positive control, negative control, the dose I, dose II, and dose III because it has a significance value of less than 0.05 ( $\mathrm{p}<0.05)$. The same results are also shown in the infusion test results. The results of the sedative effect test of the ethanolic extract are shown in Table 2, Figure 1 and 2.

Table 2. Sedative Effect Test Result.

\begin{tabular}{l|c|c|c|c|c|c}
\multirow{2}{*}{ Test Group } & \multicolumn{3}{|c|}{ Extract etanolic } & \multicolumn{3}{c}{ Infusion } \\
\cline { 2 - 7 } & \multicolumn{2}{|c|}{ Traction Test } & Fireplace Test & \multicolumn{2}{c}{ Traction Test } & Fireplace Test \\
\cline { 2 - 7 } & $\begin{array}{c}\text { return time } \\
(\mathbf{s e c})\end{array}$ & $\begin{array}{c}\text { fall time } \\
(\mathbf{s e c})\end{array}$ & $\begin{array}{c}\text { Jump Time } \\
(\mathbf{s e c})\end{array}$ & $\begin{array}{c}\text { return time } \\
(\mathbf{s e c})\end{array}$ & $\begin{array}{c}\text { fall time } \\
(\mathbf{s e c})\end{array}$ & $\begin{array}{c}\text { Jump Time } \\
(\mathbf{s e c})\end{array}$ \\
\hline Positive control & 1.07 & 2.20 & 44.1 & 3.12 & 0.94 & 43.62 \\
\hline Negative control & 0.7 & - & 1.07 & 1.18 & - & 1.20 \\
\hline Doses I & 0.83 & - & 11.2 & 1.62 & - & 4.24 \\
\hline Doses II & 1.10 & 2.11 & 46.7 & 2.08 & 7.50 & 13.40 \\
\hline Doses III & 1.37 & 1.50 & 64.7 & 2.54 & 6.10 & 39.86
\end{tabular}

Positive control group (diazepam), negative control (CMC 1\% + aquadest), ethanol extract doses III: $12.14 \mathrm{mg} /$ $20 \mathrm{gBB}$; ethanol extract doses II: $24.29 \mathrm{mg} / 20 \mathrm{gBB}$; ethanol extract doses I: $48.57 \mathrm{mg} / 20 \mathrm{gBB}$; kratom leaf infusion doses III: $39 \mathrm{mg} / 20 \mathrm{gBB}$; kratom leaf infusion doses II: $78 \mathrm{mg} / 20 \mathrm{gBB}$; and kratom leaf infusion doses I: $156 \mathrm{mg} /$ $20 \mathrm{gBB}$.
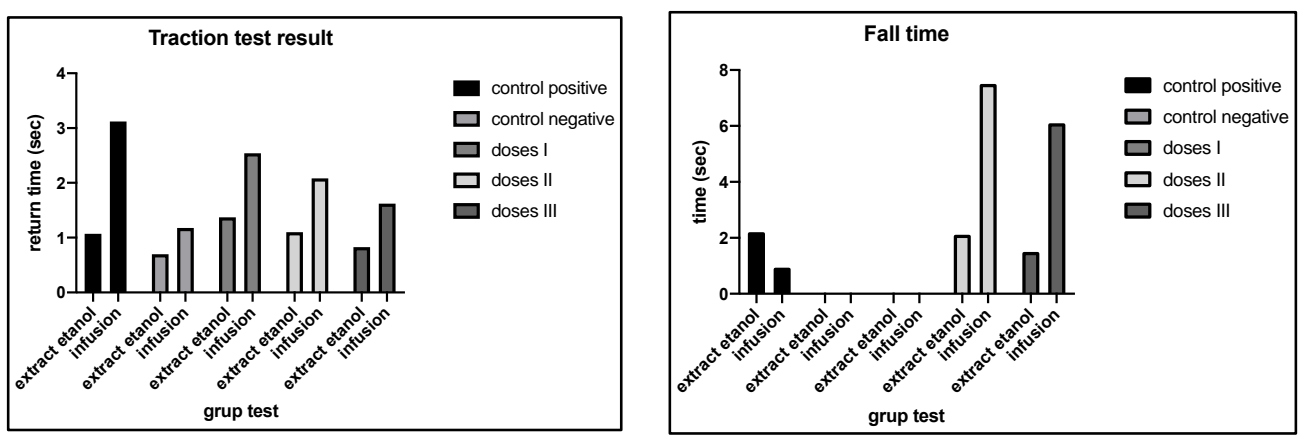

Figure 1. Result of Traction test.

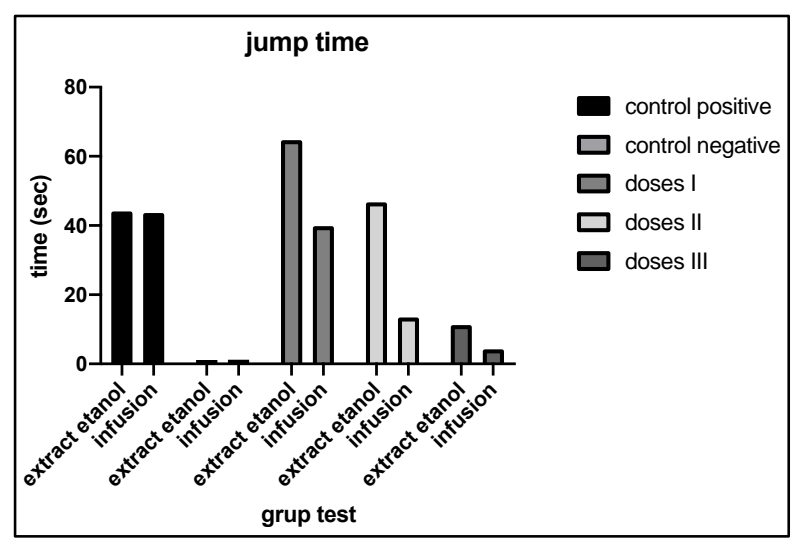

Figure 2. Result of Fireplace test.

The test results show the average time of each test parameter with the traction test and fireplace test methods. Based on the result, the group test gave the most significant sedative effect at dose I, followed by dose group II and dose III.

The results of data analysis for the turning time parameter showed that the negative control treatment group had a significant difference $(\mathrm{p}<0.05)$ with the positive control treatment group, dose II and dose III (fig 1). That means that the positive control treatment group, dose II and I, had a potential sedative effect, while dose III did not. Increasing doses of ethanol extract of kratom leaves, there is an increase in the sedative effect. The stimulating effect of 
ethanol extract and infusion of kratom leaves selected for the turning time parameter in this study is dose II.

Qualitative data in corneal and turning reflexes obtained from the study results also showed a decreased activity. The negative control treatment group did not change these parameters 120 minutes, but in each positive control treatment group, dose III, dose II, and dose I showed a change. The positive control group showed a change in the corneal reflex and turning the body after 10 minutes. This change indicates that the drug began to have a sedative effect in this group at 10 minutes. The results of observations in the group test at dose III showed a change in corneal reflex after 15 minutes, but there was no change in the back reflex in 120 minutes. This change indicates that the test animals are transitioning from a stimulant effect to a sedative effect. The decrease in muscle tone activity only occurs in the eye area. The observations for the group test at doses I and II showed that changes in corneal reflex occurred in 10 to 15 minutes, while the change in back reflex occurred in 60 minutes. This change means that the extract ethanol and infusion have taken effect in 10-15 minutes.

The main components of kratom leaves are indole alkaloids, namely. Mitragynine $(66.2 \%)$ and 7-hydroxy mitragynine $(2.0 \%)$ [9, 14, 21, 22]. Mitragynine showed a significant decrease in locomotor activity in rats. At the same time, 7-hydroxy mitragynine acts on nerve endings and inhibits the release of neurotransmitters [9, 10, 12, 15, 21, 22]. The alkaloid compounds contained in kratom leaves may have sedative activity. Alkaloids have an agonist effect on the GABA (gamma-aminobutyric acid) receptor. GABA released from nerve terminals binds to GABA receptors; this binding causes the opening of chloride channels. Nerve cell membranes usually are impermeable to chloride ions. However, when chloride channels are open, they allow chloride ions to enter, increasing the electrical potential across the cell membrane, making it difficult to excite and causing sedative effect hypnosis. However, other compounds likely cause a sedative effect, such as chrysin (flavonoid) in the herb Passiflora incarnata L [15, 21]. In vitro, chrysin can bind to benzodiazepine receptors. Its mechanism of action is by reducing locomotor activity in animals induced by pentobarbital.

\section{Conclusions}

The results showed that the ethanol extract and leaf infusion kratom has a sedative effect on male mice of BALB/c strain. The effective dose of ethanol extract of kratom leaves is a dose of $48.57 \mathrm{mg} / 20 \mathrm{gBW}$ and $7.80 \mathrm{~g} / \mathrm{kgBB}$ in infusion.

\section{Funding}

This research received no external funding.

\section{Acknowledgments}

We thank all parties who helped in this research, especially the biology pharmacy and pharmacology laboratory, Faculty of Medicine, Universitas Tanjungpura.

\section{Conflicts of Interest}

The authors declare no conflict of interest. 


\section{References}

1. Fernandez-Mendoza, J.; Vgontzas, A.N. Insomnia and its Impact on Physical and Mental Health. Current Psychiatry Reports 2013, 15, 418-418, https://doi.org/10.1007/s11920-013-0418-8.

2. Lundh, L.G. Morin, cm: Insomnia: Psychological assessment and management. Scandinavian Journal Of Behaviour Therapy 1994, 23, 62-62.

3. Roth, T. Insomnia: definition, prevalence, etiology, and consequences. Journal of clinical sleep medicine 2007, 3, S7-S10.

4. Choueiry, N.; Salamoun, T.; Jabbour, H.; El Osta, N.; Hajj, A.; Rabbaa Khabbaz, L. Insomnia and Relationship with Anxiety in University Students: A Cross-Sectional Designed Study. PLOS ONE 2016, 11, https://doi.org/10.1371/journal.pone.0149643.

5. Edinger, J.D.; Sampson, W.S. A Primary Care "Friendly" Cognitive Behavioral Insomnia Therapy. Sleep 2003, 26, 177-182, https://doi.org/10.1093/sleep/26.2.177.

6. Griffin, C.E.; Kaye, A.M.; Bueno, F.R.; Kaye, A.D. Benzodiazepine pharmacology and central nervous system-mediated effects. Ochsner Journal 2013, 13, 214-223.

7. Rosenbaum, J.F. Benzodiazepines: A Perspective. American Journal of Psychiatry 2020, 177, 488-490, https://doi.org/10.1176/appi.ajp.2020.20040376.

8. Schmitz, A. Benzodiazepine use, misuse, and abuse: A review. Mental Health Clinician 2016, 6, 120-126, https://doi.org/10.9740/mhc.2016.05.120.

9. Moklas, M.A.M.; Nurul Raudzah, A.R.; Taufik Hidayat, M.; Sharida, F.; Farah Idayu, N.; Zulkhairi, A.; Shamima, A.R. A preliminary toxicity study of mitragynine, an alkaloid from Mitragyna speciosa Korth and its effects on locomotor activity in rats. Adv. Med. Dent. Sci 2008, 2, 56-60.

10. Meireles, V.; Rosado, T.; Barroso, M.; Soares, S.; Gonçalves, J.; Luís, Â.; Caramelo, D.; Simão, A.Y.; Fernández, N.; Duarte, A.P.; Gallardo, E. Mitragyna speciosa: Clinical, Toxicological Aspects and Analysis in Biological and Non-Biological Samples. Medicines 2019, 6, https://doi.org/10.3390/medicines6010035.

11. Flores-Bocanegra, L.; Raja, H.A.; Graf, T.N.; Augustinović, M.; Wallace, E.D.; Hematian, S.; Kellogg, J.J.; Todd, D.A.; Cech, N.B.; Oberlies, N.H. The Chemistry of Kratom [Mitragyna speciosa]: Updated Characterization Data and Methods to Elucidate Indole and Oxindole Alkaloids. Journal of Natural Products 2020, 83, 2165-2177, https://doi.org/10.1021/acs.jnatprod.0c00257.

12. Todd, D.A.; Kellogg, J.J.; Wallace, E.D.; Khin, M.; Flores-Bocanegra, L.; Tanna, R.S.; McIntosh, S.; Raja, H.A.; Graf, T.N.; Hemby, S.E.; Paine, M.F.; Oberlies, N.H.; Cech, N.B. Chemical composition and biological effects of kratom (Mitragyna speciosa): In vitro studies with implications for efficacy and drug interactions. Scientific Reports 2020, 10, https://doi.org/10.1038/s41598-020-76119-w.

13. Kapp, F.G.; Maurer, H.H.; Auwärter, V.; Winkelmann, M.; Hermanns-Clausen, M. Intrahepatic Cholestasis Following Abuse of Powdered Kratom (Mitragyna speciosa). Journal of Medical Toxicology 2011, 7, 227 231, https://doi.org/10.1007/s13181-011-0155-5.

14. Kruegel, A.C.; Uprety, R.; Grinnell, S.G.; Langreck, C.; Pekarskaya, E.A.; Le Rouzic, V.; Ansonoff, M.; Gassaway, M.M.; Pintar, J.E.; Pasternak, G.W.; Javitch, J.A.; Majumdar, S.; Sames, D. 7Hydroxymitragynine Is an Active Metabolite of Mitragynine and a Key Mediator of Its Analgesic Effects. ACS Central Science 2019, 5, 992-1001, https://doi.org/10.1021/acscentsci.9b00141.

15. Kruegel, A.C.; Gassaway, M.M.; Kapoor, A.; Váradi, A.; Majumdar, S.; Filizola, M.; Javitch, J.A.; Sames, D. Synthetic and Receptor Signaling Explorations of the Mitragyna Alkaloids: Mitragynine as an Atypical Molecular Framework for Opioid Receptor Modulators. Journal of the American Chemical Society 2016, 138, 6754-6764, https://doi.org/10.1021/jacs.6b00360.

16. Shamima, A.R.; Fakurazi, S.; Hidayat, M.T.; Hairuszah, I.; Moklas, M.A.M.; Arulselvan, P. Antinociceptive Action of Isolated Mitragynine from Mitragyna Speciosa through Activation of Opioid Receptor System. International Journal of Molecular Sciences 2012, 13, https://doi.org/10.3390/ijms130911427.

17. Manning, D.P.; Jones, C.; Bruce, M. Proof of shoe slip-resistance by a walking traction test. Journal of Occupational Accidents 1990, 12, 255-270, https://doi.org/10.1016/0376-6349(90)90050-6.

18. Raab, E.L. Traction Test. Archives of Ophthalmology 1977, 95, 1649-1649, https://doi.org/10.1001/archopht.1977.04450090171017.

19. Chung, W.-T.; Lei, M.-Y.; Tsai, K.-C. Evaluating current fire test methods for determining flammability performance of ceiling materials. Journal of Marine Science and Technology 2014, 22, 196-203, https://doi.org/10.6119/JMST-013-0311-1.

20. Ali, S.; Hussain, S.A.; Tohir, M.Z.M. Fire Test and Effects of Fire Retardant on the Natural Ability of Timber: A Review. Pertanika Journal of Science \& Technology 2019, 27.

21. Matsumoto, K.; Horie, S.; Ishikawa, H.; Takayama, H.; Aimi, N.; Ponglux, D.; Watanabe, K. Antinociceptive effect of 7-hydroxymitragynine in mice: Discovery of an orally active opioid analgesic from the Thai medicinal herb Mitragyna speciosa. Life Sciences 2004, 74, 2143-2155, https://doi.org/10.1016/j.lfs.2003.09.054.

22. Takayama, H. Chemistry and Pharmacology of Analgesic Indole Alkaloids from the Rubiaceous Plant, Mitragyna speciosa. Chemical and Pharmaceutical Bulletin 2004, 52, 916-928, https://doi.org/10.1248/cpb.52.916. 